\title{
Angiographic Profile and Treadmill Test Relationship of Women with Chest Pain Suggestive of Coronary Artery Disease
}

\author{
Stanley George \\ Department of Cardiology, Pariyaram Medical College, Kannur, India \\ Email: s4stanley@gmail.com
}

How to cite this paper: George, S. (2017) Angiographic Profile and Treadmill Test Relationship of Women with Chest Pain Suggestive of Coronary Artery Disease. World Journal of Cardiovascular Diseases, 7, 225232.

https://doi.org/10.4236/wjcd.2017.78021

Received: June 8, 2017

Accepted: August 1, 2017

Published: August 4, 2017

Copyright $\odot 2017$ by author and Scientific Research Publishing Inc. This work is licensed under the Creative Commons Attribution International License (CC BY 4.0).

http://creativecommons.org/licenses/by/4.0/

\section{cc) (i) Open Access}

\begin{abstract}
Aim: The aim of present study was to analyze the prevalence and pattern of coronary artery disease (CAD) among women who underwent coronary angiography (CAG) and Treadmill Test (TMT). Methods: A total of 100 consecutive women patients for coronary angiogram were studied at Department of Cardiology, Government Medical College, Kottayam, Kerala, India on over a period of 6 months from February 2008. Total 65 women completed TMT stress test. The patients were subjected to CAG and TMT. Data were analyzed by using SPSS 20.0 software. Results: A total of 100 women patients were included. Among that $66 \%$ patients had hypertension and $47 \%$ patients had diabetes mellitus. The CAG revealed the presence of $17 \%, 13 \%$ and $15 \%$ of single vessel disease, double vessel disease, and triple vessel disease respectively. Vessel involvements were notably higher in positive TMT values during stress test. The sensitivity and specificity of TMT for detecting coronary artery disease in women were $61 \%$ and $69 \%$ respectively. Conclusion: It is concluded that, the findings of the present study effectively demonstrated higher predictive value of TMT in women with chest pain suggestive of CAD.
\end{abstract}

\section{Keywords}

Coronary Angiography, Coronary Artery Disease, Treadmill Test

\section{Introduction}

Coronary artery disease (CAD) is a leading cause of morbidity and mortality in human beings. Previously it was considered as a disease of Western Nations, but now it is equally prevalent in developed and developing nations [1]. Globally, there has been a significant rise in the proportion of women suffer from CAD 
over the last few decades. The causes for this evolutionary change may be genetic or environmental factors. The preliminary step was to identify these changes using angiographic profiles of women suffering from CAD. In addition, exercise stress test or "Treadmill Test" (TMT) remains a cost-effective and widely applicable approach for assessing myocardial ischemia, but has a relatively low specificity and sensitivity, mainly in single and double vessel disease [2] [3]. The prevalence and pattern of CAD in women who underwent coronary angiography (CAG) and TMT was very less.

When symptoms are atypical or non-specific, TMT in women has a relatively low analytical tools yield for CAD compared with men. Therefore, there was need of angiographic prevalence and pattern of CAD in women. The earlier researcher reported that $70 \%$ of sensitivity and $61 \%$ of specificity of TMT for detection of CAD in women [4]. Stenosis of the left main coronary artery (LMCA) is a comparatively rare but significant cause of augmented morbidity and mortality among patients with CAD. Left anterior descending (LAD) is the most commonly affected vessel, followed by LCX and RCA, and LMCA was the least involved vessel [5].

During exercise, catecholamine was released predominantly in women, which could potentiate coronary vasospasm and enhance the frequency of abnormal exercise. False positive results have been represented commonly during menses and pre-ovulation. The previous finding from a meta-analysis elucidated that a specificity of $70 \%$ suggests false positivity of approximately $30 \%$ in TMT positive patients [4].

The aim of the present study was to analyze the coronary artery profile using coronary angiography and treadmill test in CAD and/or chest pain women patients.

\section{Material and Method}

This study was conducted on one hundred consecutive women patients who have chest pain conducted for coronary angiogram at Department of Cardiology, Government Medical College, Kottayam, Kerala, India over a period of 6 months from February 2008.

In this study, we have included women patients with chest pain were at least 30 years of age, who had a history of either diabetes mellitus and/or hypertension. Patients were excluded if they had pervious coronary artery bypass graft, PTCA and valvular heart disease. Detailed history of patients was recorded on basis of nature of chest pain. Pulse, blood pressure and JVP (jugular venous pressure) examination was done. Anemia, jaundice, Cyanosis, Pedal edema, approximate fat and palpable heart sounds or murmurs were examined. The Bruce protocol was used for stress testing. In resting 12 lead ECG was performed and each lead placed on the body records the electrical activity of the heart. There are three leads that are connected to the Treadmill monitor. During the stress test, the patient's blood pressure was recorded at the second minute in every stage. 
The positive predictive value was determined according to the following formula: PPV = True Positive/(True Positive + False Positive). Written informed consent was obtained from all patients before enrolment, and the study was approved by the local ethical committee.

\section{Statistical Analysis}

Categorical variables were expressed as percentages. The SPSS 20.0 software (SPSS Inc., Chicago, IL, USA) was used to analyze the data.

\section{Results}

\subsection{Baseline, Lesion and Procedural Characteristics}

The baseline demographics of the patients are outlined in Table 1. A total of 100 women data were collected and analyzed in this study. Out of 100 women, $47 \%$ had diabetes, $66 \%$ had hypertensive and $36 \%$ had both diabetes and hypertension. Among 100 patients, $55 \%$ and $24 \%$ patients were treated with stable angina and unstable angina/non-ST-elevation myocardial infarction. A total of $16 \%$ patients had previous MI and 15\% silent ischemia. Details of the lesion and procedural characteristics are outlined in Table 2. Among the 100 patients under assessment, single vessel disease (SVD) was the most common (17\%) followed by $15 \%$ of triple vessel disease (TVD) and 13\% of double-vessel disease (DVD). Left anterior descending (LAD) artery disease was seen in $38 \%$ followed by right coronary artery (RCA) 29\%, left circumflex artery (LCx) $23 \%$, and left main coronary artery (LMCA) in 5\%. Minor coronary artery disease was present in $26 \%$ of

Table 1. Baseline demographic data of the patients.

\begin{tabular}{cc}
\hline Variable & N $=100$ Patients \\
\hline Age years & $9(9 \%)$ \\
$30-40$ & $24(24 \%)$ \\
$41-50$ & $43(43 \%)$ \\
$51-60$ & $17(17 \%)$ \\
$61-70$ & $7(7 \%)$ \\
$>70$ & $47(47 \%)$ \\
Diabetes mellitus, n (\%) & $66(66 \%)$ \\
Hypertension, n (\%) & $36(36 \%)$ \\
\hline Both diabetes mellitus and hypertension, $\mathrm{n}(\%)$ & $55(55 \%)$ \\
\hline Clinical presentation & $24(24 \%)$ \\
\hline Stable angina, $\mathrm{n}(\%)$ & $16(16 \%)$ \\
Unstable angina/NSTEMI, n (\%) & $05(5 \%)$ \\
Previous MI, n (\%) & $15(15 \%)$ \\
\hline Silent ischemia, n (\%) &
\end{tabular}

NSTEMI: Non-ST-elevation myocardial infarction; MI: Myocardial infarction. 
Table 2. Lesion and angiographic characteristics.

\begin{tabular}{cc}
\hline Variables & $\mathrm{n}=116$ Lesions \\
\hline Lesion location, $\mathbf{n}(\%)$ & \\
\hline LAD, $\mathrm{n}(\%)$ & $38(38 \%)$ \\
RCA, $\mathrm{n}(\%)$ & $29(29 \%)$ \\
LCx, $\mathrm{n}(\%)$ & $23(23 \%)$ \\
LMCA, $\mathrm{n}(\%)$ & $5(5 \%)$ \\
\hline Number of diseases vessels & $17(17 \%)$ \\
\hline Single vessel disease, $\mathrm{n}(\%)$ & $13(13 \%)$ \\
Double vessel disease, $\mathrm{n}(\%)$ & $15(15 \%)$ \\
Triple vessel disease, $\mathrm{n}(\%)$ & $26(26 \%)$ \\
Minor CAD & $(24 \%)$ \\
\hline Normal coronary artery & \\
\hline
\end{tabular}

LMCA: Left main coronary artery; LAD: Left anterior descending artery; LCx: Left circumflex artery; RCA: Right coronary artery; CAD: Coronary artery disease.

cases and $24 \%$ of patients had normal coronaries.

\subsection{Stress Test (TMT) and Coronary Angiography Findings}

A total of 100 patients underwent TMT test, of which $65 \%$ of patients completed stress test (Figure 1). Out of 65 patients, 33 patients had a positive test and 32 patients had a negative/inconclusive test. From this study, it was found that $18.2 \%$ of diabetes patients had negative TMT test and $15.1 \%$ had a positive test. Similarly, $21.2 \%$ of hypertensive patients had a negative TMT test and $27.3 \%$ had a positive TMT. In those patients having both diabetes and hypertension 21.2\% had a negative TMT and $36 \%$ had a positive TMT (Figure 2).

Table 3 depicts the correlation between vessel involvement and TMT value. It was found that higher level of positive stress test i.e. $27.1 \%, 15.1 \%$ and $36 \%$ of patients were positive TMT with SVD, DVD and TVD respectively as compared to negative TMT. However, those who were having normal coronaries, $31.3 \%$ were having a negative TMT and $15 \%$ had positive TMT. The present study revealed significant correlation between single vessel involvement and TMT positivity $(Z=2.75 ; \mathrm{p}<0.01)$. Similarly, comparing DVD and TVD with TMT showed significant correlation $(Z=2.99 ; \mathrm{p}<0.01)$. The positive predictive value, sensitivity of TMT for detecting coronary artery disease in women was $61 \%$ and specificity was found to be $69 \%$ in the present study (Figure 3).

\section{Discussion}

The risk of morbidity and mortality from coronary artery disease increased rapidly among men and women. Even though significant research efforts have advanced diagnosis and treatment strategies for patients at risk, but the detection of CAD in women can be challenging. The predictive value of risk factors was different in women than men because atypical chest pain is more prevalent 


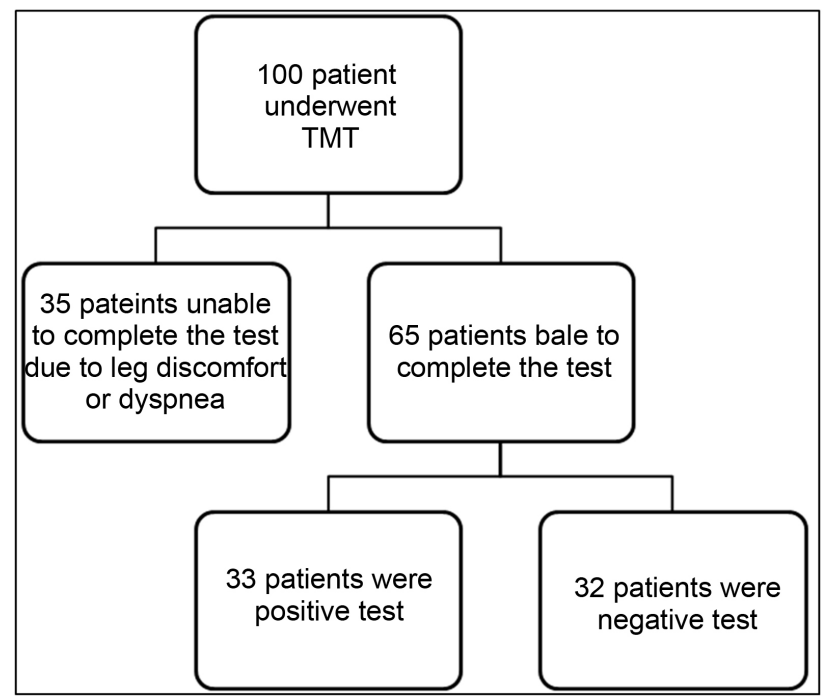

Figure 1. Flowchart of patients who underwent the exercise treadmill test (TMT).

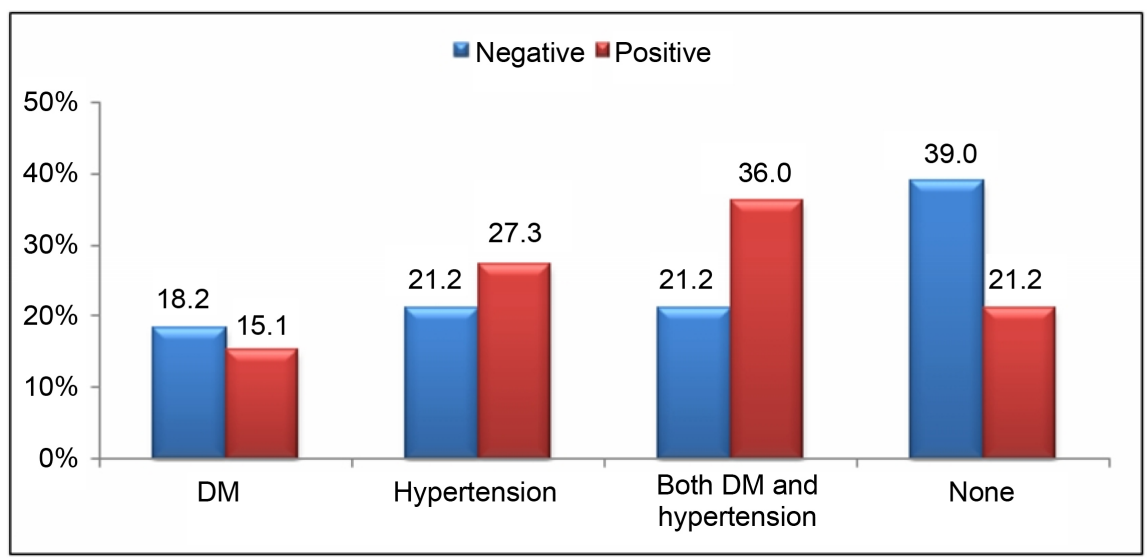

Figure 2. Correlation between TMT test and risk factors of complexity of diseases.

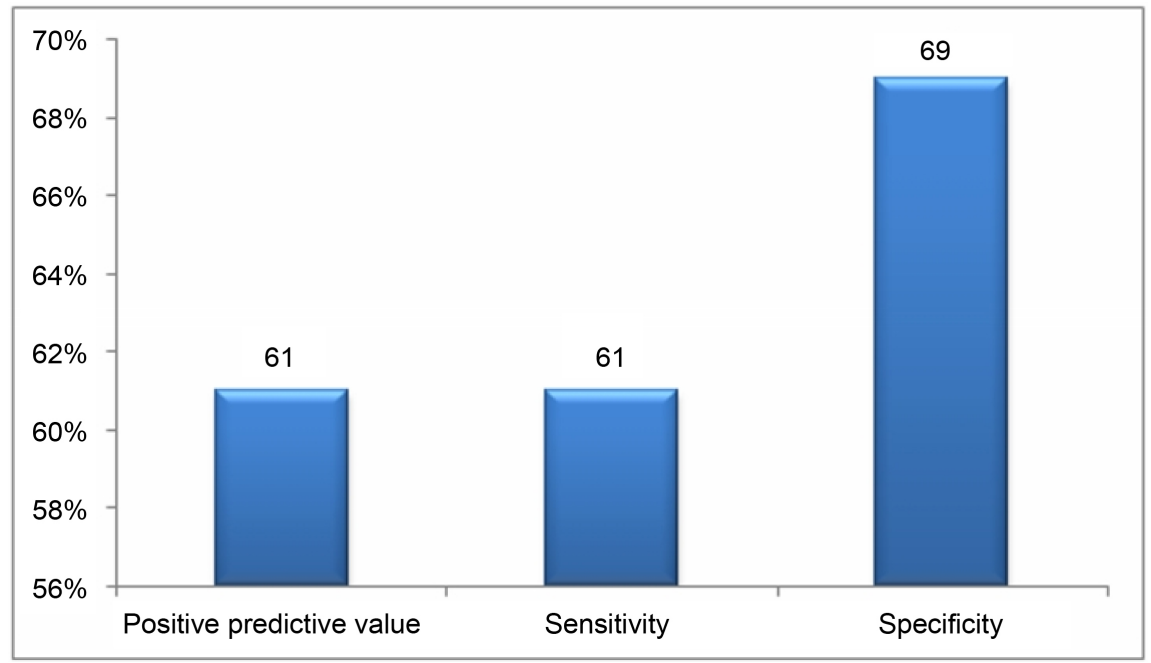

Figure 3. Predictive value, sensitivity and specificity of TMT in coronary artery disease patients. 
Table 3. Correlation between TMT test and vessel involvement.

\begin{tabular}{ccc}
\hline Vessel involvement & TMT positive & TMT negative \\
\hline SVD & $27.1 \%$ & $3.1 \%$ \\
DVD & $15.1 \%$ & $9.3 \%$ \\
TVD & $36 \%$ & $21.2 \%$ \\
LMCA & $20 \%$ & - \\
Minor coronary artery disease & $24.2 \%$ & $37.5 \%$ \\
\hline
\end{tabular}

SVD: Single vessel disease; DVD: Double vessel disease; TVD: Triple vessel disease; LMCA: Left main coronary artery.

among women. Hence, women in this study were classified according to different ages from 30 to $>70$ years. There has been a varying trend in the number of young and middle-aged women (41 to 60 years) undergoing coronary angiography and the reason for this is the onset of risk factors for CAD at younger and middle age. The complexity of diseases condition like diabetes mellitus and hypertension or presence of both varies between different age groups. Modifications of dietary habit and lifestyle improve the incidence of CAD patients.

The TMT was performed using treadmill bicycle exercise with ECG, blood pressure and heart rate monitoring. Contraindications for TMT are symptomatic heart failure, acute myocardial infarction, symptomatic aortic stenosis, acute arrhythmia, accelerated hypertension (Blood pressure > 200/110), aortic dissection, and AV blocks. The diagnostic accuracy of exercise testing varies depending on the age, clinical characteristics of the patient and modality of test used [6]. Similar to the diagnostic data, there have been voluminous amount of single-centre studies outcome demonstrated the stress test as diagnostic tool in women with CAD [7] [8] [9] [10].

The meta-analyses data in the published literature elucidated the analytical accuracy of stress testing for the presence of obstructive CAD, identified as 50\% diameter or more stenosis by quantitative coronary angiography (QCA) [11] [12] [13]. Exercise stress test has been represented to have a sensitivity of $61 \%$ and specificity of $69 \%$ for the detection of CAD in women. In our study, 65 patients completed stress test out of 100 patients. Of these 65 patients, positive TMT were $36 \%$ cases of both hypertension and diabetes mellitus, while $27.3 \%$ and $15.1 \%$ women with hypertension and diabetes mellitus condition have positive TMT respectively. Hence, the presence of complexity of disease leads to more risk of CAD. Moreover, discussion on the correlation between diabetes and $\mathrm{CAD}$ continues, and numerous current studies have reported a positive relationship [14] [15].

In our study, 35 patients (35\%) were unable to complete the TMT test, mostly due to leg discomfort or dyspnea. The TMT is often not feasible for diabetic and hypertensive patients because their exercise capability may be impaired. In addition, the presence of lesions in a number of disease vessels is an important risk factor to correlate with TMT test. Our result showed that 27.1\%, 15.1\% and 36\% of patients were positive stress test with SVD, DVD and TVD respectively. LAD 
is the most commonly affected vessel, followed by involvement of LCx and RCA, and LMCA is the least involved vessel. However, atypical chest pain with normal coronaries patients has $31.3 \%$ negative TMT test. Similarly, minor CAD patients have $24.2 \%$ and $37.5 \%$ of positive and negative TMT respectively. In the absence of symptomatic CAD, clinical characteristics that assist to classify patients with an elevated risk for myocardial infarction or cardiac death include evidence of other atherosclerosis, abnormal resting ECGs, autonomic neuropathy, retinopathy, chronic kidney disease, age, sex, hyperglycemia and novel cardiac risk factors [16].

The positive predictive value of the TMT for predicting angiographic coronary disease was $61 \%$. It is therefore concluded that the magnitude of exercise definitely improves the predictive value of treadmill tests and helps in the identification of patients with more severe coronary heart disease.

\section{Limitations}

First limitation is the small number of subjects recruited in our study. Second limitation is unavailability of information on conventional cardiovascular disease risk factors, such as a history of premature CAD, retinopathy and autonomic neuropathy.

\section{Conclusion}

In conclusion, associations of vessels involvement were considerably correlated with positive TMT values. These finding have shown that the higher predictive value of TMT with chest pain indicative of CAD in women patients. Further research is needed to ascertain the effectiveness of schedule screening for asymptomatic $\mathrm{CAD}$ and chest pain in a different patient subgroup.

\section{Conflict of Interest}

All authors have no conflicts of interest to declare.

\section{References}

[1] Celermajer, D.S., Chow, C.K., Marijon, E., Anstey, N.M. and Woo, K.S. (2012) Cardiovascular Disease in the Developing World: Prevalences, Patterns, and the Potential of Early Disease Detection. Journal of the American College of Cardiology, 60, 1207-1216. https://doi.org/10.1016/j.jacc.2012.03.074

[2] Bruce, R.A., DeRouen, T.A., Hossack, K.F., Blake, B. and Rn Hofer, V. (1980) Value of Maximal Exercise Tests in Risk Assessment of Primary Coronary Heart Disease Events in Healthy Men. The American Journal of Cardiology, 46, 371-378. https://doi.org/10.1016/0002-9149(80)90003-X

[3] Froelicher Jr., V.F., Yanowitz, F.G., Thompson, A.J. and Lancaster, M.C. (1973) The Correlation of Coronary Angiography and the Electrocardiographic Response to Maximal Treadmill Testing in 76 Asymptomatic Men. Circulation, 48, 597-604. https://doi.org/10.1161/01.CIR.48.3.597

[4] Junker, J., Meyer, A., Flake, D. and Montgomery, L. (2004) Clinical Inquiries. Is Exercise Treadmill Testing Useful for Detecting Heart Disease in Women? The Jour- 
nal of Family Practice, 53, 321-324.

[5] Welch, C.C., Proudfit, W.L. and Sheldon, W.C. (1975) Coronary Arteriographic Findings in 1,000 Women under Age 50. The American Journal of Cardiology, 35, 211-215. https://doi.org/10.1016/0002-9149(75)90003-X

[6] DeCara, J.M. (2003) Noninvasive Cardiac Testing in Women. Journal of the American Medical Women's Association, 58, 254-263.

[7] Metz, L.D., Beattie, M., Hom, R., Redberg, R.F., Grady, D. and Fleischmann, K.E. (2007) The Prognostic Value of Normal Exercise Myocardial Perfusion Imaging and Exercise Echocardiography: A Meta-Analysis. Journal of the American College of Cardiology, 49, 227-237. https://doi.org/10.1016/j.jacc.2006.08.048

[8] Navare, S.M., Mather, J.F., Shaw, L.J., Fowler, M.S. and Heller, G.V. (2004) Comparison of Risk Stratification with Pharmacologic and Exercise Stress Myocardial Perfusion Imaging: A Meta-Analysis. Journal of Nuclear Cardiology: Official Publication of the American Society of Nuclear Cardiology, 11, 551-561. https://doi.org/10.1016/j.nuclcard.2004.06.128

[9] Peteiro, J., Monserrrat, L., Pineiro, M., Calvino, R., Vazquez, J.M., Marinas, J. and Castro-Beiras, A. (2006) Comparison of Exercise Echocardiography and the Duke Treadmill Score for Risk Stratification in Patients with Known or Suspected Coronary Artery Disease and Normal Resting Electrocardiogram. American Heart Journal, 151, 1324.e1321-1310. https://doi.org/10.1016/j.ahj.2006.03.015

[10] Bangalore, S., Gopinath, D., Yao, S.S. and Chaudhry, F.A. (2007) Risk Stratification Using Stress Echocardiography: Incremental Prognostic Value over Historic, Clinical, and Stress Electrocardiographic Variables across a Wide Spectrum of Bayesian Pretest Probabilities for Coronary Artery Disease. Journal of the American Society of Echocardiography: Official Publication of the American Society of Echocardiography, 20, 244-252. https://doi.org/10.1016/j.echo.2006.08.014

[11] Gianrossi, R., Detrano, R., Mulvihill, D., Lehmann, K., Dubach, P., Colombo, A., McArthur, D. and Froelicher, V. (1989) Exercise-Induced ST Depression in the Diagnosis of Coronary Artery Disease. A Meta-Analysis. Circulation, 80, 87-98. https://doi.org/10.1161/01.CIR.80.1.87

[12] Fleischmann, K.E., Hunink, M.G., Kuntz, K.M. and Douglas, P.S. (1998) Exercise Echocardiography or Exercise SPECT Imaging? A Meta-Analysis of Diagnostic Test Performance. The Journal of the American Medical Association, 280, 913-920. https://doi.org/10.1001/jama.280.10.913

[13] Geleijnse, M.L., Krenning, B.J., van Dalen, B.M., Nemes, A., Soliman, O.I., Bosch, J.G., Galema, T.W., Ten Cate, F.J. and Boersma, E. (2009) Factors Affecting Sensitivity and Specificity of Diagnostic Testing: Dobutamine Stress Echocardiography. Journal of the American Society of Echocardiography. Official Publication of the American Society of Echocardiography, 22, 1199-1208. https://doi.org/10.1016/j.echo.2009.07.006

[14] Janand-Delenne, B., Savin, B., Habib, G., Bory, M., Vague, P. and Lassmann-Vague, V. (1999) Silent Myocardial Ischemia in Patients with Diabetes: Who to Screen. Diabetes Care, 22, 1396-1400. https://doi.org/10.2337/diacare.22.9.1396

[15] Yoo, W.S., Kim, H.J., Kim, D., Lee, M.Y. and Chung, H.K. (2009) Early Detection of Asymptomatic Coronary Artery Disease in Patients with Type 2 Diabetes Mellitus. The Korean Journal of Internal Medicine, 24, 183-189. https://doi.org/10.3904/kjim.2009.24.3.183

[16] Bax, J.J., Young, L.H., Frye, R.L., Bonow, R.O., Steinberg, H.O. and Barrett, E.J. (2007) Screening for Coronary Artery Disease in Patients with Diabetes. Diabetes Care, 30, 2729-2736. https://doi.org/10.2337/dc07-9927 
Submit or recommend next manuscript to SCIRP and we will provide best service for you:

Accepting pre-submission inquiries through Email, Facebook, LinkedIn, Twitter, etc. A wide selection of journals (inclusive of 9 subjects, more than 200 journals)

Providing 24-hour high-quality service

User-friendly online submission system

Fair and swift peer-review system

Efficient typesetting and proofreading procedure

Display of the result of downloads and visits, as well as the number of cited articles Maximum dissemination of your research work

Submit your manuscript at: http://papersubmission.scirp.org/

Or contact wicd@scirp.org 